\title{
The Evolution of the Nursing Profession Post Genocide
}

\author{
Mary Murebwayire ${ }^{1}$, Innocent Biroli ${ }^{2}$, Helen Ewing ${ }^{2}$ \\ ${ }^{1}$ Ministry of Health, Rwanda \\ ${ }^{2}$ University of Rwanda, College of Medicine and Health Sciences, Rwanda
}

\section{Background}

Nurses and midwives play a pivotal role in ensuring that patients get quality care and form the largest portion of the Rwandan health workforce. Rwandan nursing has continued to suffer constraints that hinder the ability to offer quality of care. Educating midwives and allied professionals was limited before the Genocide. Reviewing the history of nursing post genocide in Rwanda is important as it provides direction and structure for the future of nursing education.

\section{Historical Review}

In 1995 the nursing division was created within the structure of the Ministry of Health $(\mathrm{MoH})$ to strengthen nursing education and practices. In 1997, in collaboration with the $\mathrm{MoH}$, Minister of Education, AMREF Health Africa, and the World Health Organization, health professionals who had returned to Rwanda joined efforts to start the Kigali Health Institute (KHI). Educating Registered Nurses, Registered Midwives, Psychiatric Nurses and Allied health professionals was initiated. After three years, KHI started showing results by graduating health professionals.

In 2006, the first nurse and midwives educators were trained. In 2007 the number of Nursing and Midwifery Schools increased to five, with approximately 200 midwives and 500 nurses graduating each year. These graduates worked in hospitals, schools of nursing and midwifery, and the health centers.

In 2012, the e-learning program was launched in five nursing and midwifery schools to upgrade the associate nurses to diploma level. The first cohort of 298 students completed their program in October 2014. Recently the National Council of Nurses and Midwives was established to regulate the professions. Rwanda nurses continue to be active in joining and collaborating with global nursing organizations to share experiences with other nurses and midwives worldwide to improve global health care delivery.

\section{Conclusion}

Better understanding of the history of nursing in Rwanda post-genocide can help guide the future direction of nursing education, leadership priorities, and policy development.

Key words: nursing, leadership, history, nursing councils, education 